\title{
Is the widely used two-factor structure of the Ruminative Responses Scale invariant across different samples of women?
}

Paola Lucena-Santos ${ }^{\text {a* }}$, José Pinto-Gouveia ${ }^{a}$, Sérgio A. Carvalho ${ }^{\text {a }}$ \& Margareth da Silva

\author{
Oliveira $^{\mathrm{b}}$
}

\begin{abstract}
${ }^{a}$ Cognitive-Behavioral Research Centre (CINEICC), Faculty of Psychology and Education Sciences, University of Coimbra, Portugal. Address: Rua do Colégio Novo, Apartado 6153. Postal Code: 3001-802. Coimbra, Portugal. ${ }^{b}$ Evaluation and Treatment in Cognitive and/or Behavioral Therapies Research Group (GAAPCC). Faculty of Psychology, Pontifical Catholic University of Rio Grande do Sul, Porto Alegre, Brazil. Address: Avenida Ipiranga, 6681 (PUCRS, Campus Central), prédio 11, sala 927. Postal Code: 90619-900. Porto Alegre, Rio Grande do Sul, Brazil.

*Corresponding author at CINEICC, Faculty of Psychology and Education Sciences, University of Coimbra, Rua do Colégio Novo, 3001-802, Coimbra, Portugal. Phone number: +351 910391274. Email address: paolabc2.lucena@gmail.com (P. Lucena-Santos).
\end{abstract}

\section{Funding sources}

This work was supported by CNPq (National Council for Scientific and Technological Development - Brazil; Reference: 408697/2013-0) and FAPERGS (Foundation for Research Support of the State of Rio Grande do Sul - Brazil; Reference: 2263-2551/14-4SIAFEM). Moreover, the first and third authors are supported by Ph.D. grants sponsored by CAPES (Coordination for the Improvement of Higher Education Personnel - Brazilian Ministry of Education; BEX Process number 0514/12-8) and FCT (Portuguese Foundation for Science and Technology), respectively. Finally, the last author is a CNPq fellowship (Research Productivity grant). None of the sponsors have participated in the design, collection, analysis, interpretation of data, writing the report, or in the decision to submit the article for publication in this journal.

\section{Conflicts of Interest}

The authors declare that there are no conflicts of interest regarding this manuscript. 


\begin{abstract}
Objectives: Although the Ruminative Responses Scale is one of the most widely used measures of rumination, its two-factor structure remains controversial. Taking this into account, we aimed to test the RRS-10 two-factor invariance (Brazilian version) between different samples of women and to study its internal consistency and convergent validity. Methods: A sample of 321 women (general population, $n=106$; college students, $n=115$; and medical population of patients with overweight and obesity, $n=100$ ) participated in the study. The two-factor structure of RRS-10 was assessed by CFA and multigroup analyses using Mplus software. Internal consistency was assessed by Cronbach's Alpha and the convergent validity by Pearson correlations. Results: The two-factor structure of RRS-10 showed a good fit, factorial invariance across three samples, good internal consistency and adequate convergent validity. Brooding and Reflection subscales were both positively correlated with psychological inflexibility, cognitive fusion, anxiety, depression and stress symptoms, although Brooding presented significantly stronger associations with these variables than Reflection. Conclusions: This study provides further discussion and evidence regarding the RRS-10 two-factor structure, as well as a valid version of RRS-10 to use in Brazil in order to reliably assess rumination in medical and research settings.
\end{abstract}

Keywords: Rumination; factorial invariance; RRS-10; psychometric properties; Brazilian version. 


\section{Practitioner Points}

- This is the first study to test and confirm the RRS two-factor structure invariance across groups.

- RRS-10 two-dimensionality was confirmed in medical and non-medical samples of women.

- Brooding subscale showed significantly stronger relationships with psychopathology and experiential avoidance than Reflection.

- The study provides evidence that RRS can be used as a valid and sound measure to accurately assess the clinically relevant dimensions of rumination simultaneously across distinct groups. 


\section{Is the widely used two-factor structure of the Ruminative Responses Scale invariant across different samples of women?}

Rumination is a psychological process characterized as a self-focused coping style that involves repetitive thinking on personal negative feelings, as well as a pattern of selfreflection on the events that have led to these feelings and/or its consequences (Lyubomirsky \& Nolen-Hoeksema, 1993; Nolen-Hoeksema, 1991), and it seems to increase the risk for developing more severe and prolonged depressive symptoms (Nolen-Hoeksema, 2004; Watkins, 2008; Nolen-Hoeksema \& Morrow, 1993).

Moreover, rumination has been described as a form of experiential avoidance (Cribb, Moulds, \& Carter, 2006), i.e., as the unwillingness to be in contact with internal experiences (such as the negative emotions and depressive mood present in ruminative thinking) that result in attempts to diminish these experiences. In fact, some authors have explored the pathway from rumination to depression and have suggest that this process is particularly nefarious when a person get entangled with internal negative experiences (e.g., such as thought, emotions, memories - i.e., cognitive fusion; Lucena-Santos, Carvalho, PintoGouveia, Gillanders, \& Oliveira, 2017). This is in line with recent theoretical approaches which propose that psychological suffering is developed/maintained not by the internal experience itself, but rather by the way a person relates to this experience (Hayes, Strosahl, \& Wilson, 2012; Greco, Lambert, \& Baer, 2008).

In fact, rumination has been implicated in a vast array of clinical problems, such as post-traumatic stress disorder (Ehring \& Ehlers, 2014), social anxiety (Abbott \& Rapee, 2004), generalized anxiety (Hoyer, Becker \& Margraf, 2002), hypomania (Knowles, Tai, Cristensen \& Bentall, 2005) and with avoidant-focused affect regulation strategies, such as non-suicidal self-injury (Hilt, Cha, \& Nolen-Hoeksema, 2008) and eating disorder 
psychopathology (Wang, Lydecker, \& Grilo, 2017, Gordon, Holm-Denoma, Troop-Gordon, \& Sand, 2012; Naumann, Tuschen-Caffier, Voderholzer, Schäfer, \& Svaldi, 2016).

Additionally, despite the known association and impact of rumination in psychological and behavioral problems, its role in medical settings is less considered. However, there is evidence that rumination is associated with poorer outcomes in medical/physical health settings (Sansone \& Sansone, 2012), such as chronic low-back pain (Le Borgne, Boudoukha, Petit, \& Roquelaure, 2017), arterial hypertension (Hogan \& Linden 2004) and chronic physical illness (see Soo, Burney, \& Basten, 2009, for a revision). Also, higher scores in rumination are associated with higher BMI in people with overweight and obesity status (Tan, Xin, Wang, \& Yao, 2017).

Above and beyond that, rumination is considered a relevant process in gender-related differences, as women are more likely to ruminate than men (Simonson, Mezulis, \& Davis, 2011; Hankin et al., 1998). One possible explanation is that rumination is a genderstereotyped coping behavior acquired by socialization through which emotional expression/responses are reinforced and internalized. Thus, in response to negative events, women tend to respond in an emotional way (see Simonson et al., 2011, for a brief revision on biological sex, gender and rumination), and have a greater tendency to present a more selffocused attention and negative affect intensity (Ingram, Cruet, Johnson, \& Wisnicki, 1988).

This theoretical interpretation seems to be in line with previous literature: ruminative thinking is associated with a significant increase in body dissatisfaction in women (Naumann et al., 2016), and it is considered an important cognitive process associated with the severity of dysfunctional eating in women with obesity (Wang et al., 2017). Thus, considering that both body dissatisfaction and body-related negative experiences are one of the most empirically stablished risk factors for the development of eating disorders (Svaldi, Naumann, Trentowska, Lackner, \& Tuschen-Caffier, 2013), it is of crucial interest to evaluate the effects 
of rumination in high risk populations such as women with overweight or obesity seeking treatment for weight loss.

Notwithstanding, in addition to being a transdiagnostic process, rumination is not exclusively present in groups of participants clinically diagnosed (or directly recruited from clinical/medical contexts), but it is extensively found in students and general population samples (Morrison \& O’Connor, 2005; Gordon et al., 2012; Knowles et al., 2005; Raes, \& Hermans, 2008, Simonson, et al., 2011; Moulds, Kandris, Starr, \& Wong, 2007; Hilt et al., 2008; O’Connor \& Noyce, 2008; Schoofs, Hermans, \& Raes, 2010).

The clinical relevance of rumination has led to the development of several measures to assess this phenomenon (e.g., Rumination on Sadness Scale - Conway, Csank, Holm, \& Blake, 2000; Stress-Reactive Rumination Scale - Alloy et al., 2000; Rumination Questionnaire - Mellings \& Alden, 2000), of which Ruminative Responses Scale (RRS; Nolen-Hoeksema \& Morrow, 1991) is one of the most widely used (e.g., Dinis, PintoGouveia, Duarte, \& Castro, 2012; Extremera \& Fernández-Berrocal, 2006; Erdur-Baker \& Bugay, 2010; Hasegawa, 2013; Lee \& Kim, 2014; Schoofs, Hermans, \& Raes, 2010; Thanoi, \& Klainin-Yobas, 2015). Nevertheless, the RRS's factor structure remains controversial. Thus, in the course of time, RRS has been subjected to several factor analyses, ending up in a shorter 10-items version (i.e., RRS-10, Treynor, Gonzalez, \& Nolen-Hoeksema, 2003) that included only those not overlapped with depression content. In the development study of the RRS-10, results from a Principal Components Analysis showed a two factor solution composed of two 5-items factors: Reflection (R) and Brooding (B). Brooding has been defined as "a passive comparison of one's current situation with some unachieved standard" while Reflection is conceptualized as "a purposeful turning inward to engage in cognitive problem solving to alleviate one's depressive symptoms" (Treynor et al., 2003, p. 256). 
Over the course of the years, several studies have explored the RRS-10 dimensionality. Overall, studies that performed a CFA analysis confirming the two-factor structure as proposed by Treynor and colleagues (2003), were conducted in non-clinical Dutch samples (Schoofs et al., 2010), high school Turkish students (Erdur-Baker \& Bugay, 2010), undergraduate Turkish students (Erdur-Baker \& Bugay, 2012), Japanese college students (Hasegawa, 2013) and college students from Thailand (Thanoi \& Klainin-Yobas, 2015). Also, some of them have also concluded the two factor model presented better fit when compared to a one-factor solution (Schoofs et al., 2010; Hasegawa, 2013).

Nevertheless, before the first CFA study on the two-dimensionality of RRS-10 (Schoofs et al., 2010), three exploratory factor analyses studies have failed to replicate the exactly RRS-10 two-factor structure originally proposed (Burwell \& Shirk, 2007; Armey et al., 2009; Whitmer \& Gotlib, 2011). In the Burwell and Shirk (2007) study, the RRS-10's items were adapted for use with adolescents by changing the wording of the items (from "depressed" to "upset"), which unable a rigorous comparison with the original items. The second exploratory study (Armey et al., 2009) claimed finding support for the twodimensional RSS's structure proposed by Treynor et al. (2003), however they only retained 8 of the 10 original items and conducted a different statistical analysis (common factor analysis instead of a principal components analysis). Moreover, the third exploratory study (Whitmer \& Gotlib, 2011) was conducted in a currently depressed group, replicating the Brooding factor but not the Reflection component. However, the authors did not perform a CFA to test whether or not the original structure would present a good model fit.

Thereafter, Griffith and Raes (2015) have conducted a CFA analysis using convenience-based community samples, which have not confirmed the RRS-10 two-factor structure. However, the authors themselves have pointed out the translation process and 
related language differences as possible reasons for these results. Additionally, the authors did not control the context in which participants have responded to the research protocol.

Therefore, considering the available findings as a whole, it is possible to conclude that the RRS-10 two-factor structure has the most solid evidence. In fact, although the two factors of RRS seem to reflect a common aspect (i.e., rumination), brooding and reflection seem to be differently related with clinical relevant variables (e.g., depression, Treynor et al., 2003; Raes \& Hermans, 2008; self-criticism, suicidal ideation, O'Connor \& Noyce, 2008), where the brooding dimension is more strongly related with those outcomes than reflection. Thus, the bi-dimensionality of RRS-10 yields relevant clinical implications as it allows a more refined way of assessing two distinctive facets of rumination that impact differently in one's course and experience of psychopathological symptoms and maladaptive behaviors.

However, it is not clear if this bi-dimensional structure would be the same across qualitatively different groups, which is pivotal to ensure that assessments and comparisons made for many years by clinicians and researchers are reliable and accurate. Additionally, as far as we know, the factor invariance of RRS-10 has never been simultaneously tested across medical (i.e., participants directly recruited from medical settings) and non-medical samples. Also, it has never been translated into Brazilian Portuguese, nor has it been analyzed psychometrically in Brazilian samples.

In order words, given the pervasive impact of rumination in the maintenance of psychopathological symptoms, the clinical importance of the distinction between its two components (i.e., brooding and reflection), its greater impairment in female individuals (including those with overweight and obesity) and the economical and time-saving properties of a sound and short measure, it is of central relevance to further examine the stability of the RRS-10 two-factor structure across groups of women. 
Thus, the main aim of this study is to test the invariance of the RRS-10 two-factor model across different groups of women (i.e., general population, college students and participants with overweight or obesity undergoing a weight loss treatment). Secondarily we aim to assess the reliability and the convergent validity of the Brazilian version of RRS-10.

\section{Methods}

\section{Design and ethical considerations}

This is a cross-sectional study included in a major project that aims to explore several psychological processes related to emotional regulation in women with overweight and obesity undergoing a weight loss treatment. The overall project was submitted and approved by the Scientific Committee of a Porto Alegre University (Rio Grande do Sul Brazilian's state) under official letter $n^{\circ}$ 014/2013, and by the Research Ethics Committee of the same institution (report $\mathrm{n}^{\circ} 386.978$ ). This research was conducted in accordance with the Helsinki Declaration. Research goals and its voluntary and confidential nature were clarified to all participants, who signed a consent form before participating in the study. The volunteers did not receive any compensation to participate in this study.

\section{Participants}

Data from three independent convenience samples of women $(N=321)$ were collected during 2014: (a) general population sample $(n=106)$ : approached to participate in the study in the Porto Alegre Bus Station and in a citizen's bureau; (b) college student sample $(n=115)$ : composed of students attending the first year of a Psychology Course; (c) medical sample ( $n=$ 100): comprised women with overweight or obesity currently in treatment for weight loss (e.g., nutrition, endocrinology or obesity consultations) in a public hospital in Porto Alegre.

The inclusion criteria were: (a) female; (b) age between 18 and 60 years; (c) 5 or more years of education, in order to diminish difficulties in reading and understanding the items. 
Additionally, participants in the medical sample had to have a Body Mass Index (BMI) $\geq 25$ $\left(\mathrm{kg} / \mathrm{m}^{2}\right.$ - Finucane et al., 2011) and to currently undergo a weight loss treatment.

While participants were filling out the research protocol, a trained member of the research team was nearby in order to clarify the items if necessary.

\section{Translation, transcultural adaptation and content validation}

After the authorization for translating, adapting and exploring the psychometric properties of RRS-10, two translations for Brazilian-Portuguese and two back-translations to English were conducted by two independent translators, both fluent in English and native in Brazilian Portuguese.

Then, a committee composed of three juries (also fluent in English and Brazilian Portuguese) who have lived in different Brazilian states - in order to ensure the Brazilian version would be understood by people from different cultural backgrounds - have discussed and decided which translation of each item should compose its preliminary version. Then, these experts in the construct assessed by RRS-10 evaluated each item from the preliminary version according to a 5-point Likert scale (1= very little; $5=$ very much) the following criteria: (a) clarity of language; (b) practical pertinence for the target culture; and (c) theoretical relevance; as oriented by Cassepp-Borges, Balbinotti and Teodoro (2010). Thereafter, these data were used to calculate the Content Validity Coefficient (CVC) as indicated by Hernández-Nieto (2002). CVC is a coefficient which varies from 0 to 1 and indicates the validity of items' content - the closer to 1 , the more the items' content present validity in regard to clarity of language, practical pertinence and theoretical relevance. All items presented $\mathrm{CVC} \geq .8$, which indicates a good content validity (Hernández-Nieto, 2002). Finally, a pilot study was conducted in a sample of 20 Brazilian adults (male and female) with different years of education in order to ensure the items would be understood by people with 
different levels of reading comprehension. Hence, since participants did not report any difficulties in understanding the items, the final RRS-10 was supported and the official data collection initiated.

\section{Measures}

Depression, Anxiety and Stress Scale (DASS-21; Lovibond \& Lovibond, 1995) is a 21-items self-report measure that assesses symptoms of depression (7-items), anxiety (7items) and stress (7-items), using a 4-point Likert scale ( $0=$ Did not apply to me at all; $4=$ Applied to me most of the time). Each item comprises a statement regarding negative emotional symptoms. Respondents should indicate the degree to which it was experienced by them in the last week. The Brazilian version showed a good internal consistency, ranging from $\alpha=.86$ and $\alpha=.92$ (Vignola $\&$ Tucci, 2014). The current study found internal consistencies of $.87, .80$ and .89 for depression, $.70, .77$ and .87 for anxiety, and $.84, .83$ and .87 for stress (in regard to general population, college students and medical samples, respectively).

Cognitive Fusion Questionnaire (CFQ-7; Gillanders et al., 2014) was developed to measure the extent to which a person tends to get entangled with their internal experiences (e.g., thoughts, emotions, and memories). This is a 7-items self-report measure in which respondents state the extent to which they experienced each described situation, using a 7point Likert scale $(1=$ Never true; $7=$ Always true $)$. Through the items' sum the total score is obtained (higher scores, indicates higher cognitive fusion levels - e.g., more entanglement with the thoughts content). The original version found internal consistencies between $\alpha=.88$ and $\alpha=.93$, and its Brazilian validation obtained $\alpha=.93$ (Lucena-Santos et al., 2017). The current study found internal consistencies of $\alpha=.93$ (for college students and general population samples) and $\alpha=0.92$ for the medical sample. 
Acceptance and Action Questionnaire (AAQ-II; Bond et al., 2011) is a self-report scale of psychological inflexibility, also used as a valid measure of experiential avoidance. It is composed by 7 items which assesses the tendency to make negative evaluations of internal experiences (e.g. "I'm afraid of my feelings"). The respondent uses a 7-point Likert scale in order to indicate the frequency in which each described situation applies to them $(1=$ Never true; $7=$ Always true). The original version revealed internal consistency of .84 and the Brazilian version showed a Cronbach's Alpha of .87 (Barbosa, 2013). In the present study the internal consistency values were very good $(\alpha=.93$ for medical sample; $\alpha=.92$ for college students sample and $\alpha=.94$ for general population sample).

Ruminative Responses Scale - short version (RRS-10, Treynor et al., 2003) is a 10items self-report measure with a 4-point Likert scale (1= almost never; $4=$ almost always $)$ comprises two subscales: Brooding (e.g. 'Think "Why do I always react this way?"; 'Think “Why do I have problems other people don't have?") and Reflection (e.g. 'Write down what you are thinking and analyze it'; 'Go someplace alone to think about your feelings'). Scores for each subscale are computed by summing its respective items. Higher scores indicates higher rumination levels. The internal consistency values observed in the original study were $\alpha=.77$ and $\alpha=.72$ for Brooding and Reflection subscales.

\section{Data analyses}

\section{Sample size}

To estimate sample size, several rules can be considered: (1) The ratio of "subjects-tovariables" (i.e., STV ratio) and/or participants per free parameters in the model ranging from 5 to 10 (Bentler \& Chou, 1987; Kass \& Tinsley, 1979; Hatcher, 1994; Nunnally, 1978), with some simulation studies suggesting ratios of 1.3 or 3.9 (Arrindell \& Van der Ende, 1985); (2) 
The magnitudes of items factor weights (the higher the magnitudes, the lower the sample size required; Velicer \& Fava, 1998; Guadagnoli \& Velicer, 1998); (3) The factors overdetermination (at least 3 or 4 variables in each factor; Velicer \& Fava, 1998; Fabrigar, Wegener, MacCallum, \& Strahan, 1999) and acceptable communalities values (Fabrigar et al, 1999).

Thus, considering our conditions (i.e., factor loadings $\geq .48$ ), average value of items communalities of 0.52 , five measured variables per factor, and STV ratios of at least $\geq 10$ (i.e., $\mathrm{STV}=10$ [medical sample], 10.6 [general population], 11.5 [college students] and 32.1 [total sample]), it is possible to conclude that we have an adequate sample size.

Nevertheless, we used the Soper's Sample Size Calculator for SEM (Soper, 2017) in order to assess our sample size adequacy specifically in the context of the RRS-10 confirmatory factor analysis. Considering a medium anticipated effect size of .3, probability level of 5\%, and statistical power $\geq .8$, at least 90 participants would be required to detect effect, and a recommended minimum sample size for model structure would be $n=100$ in each sample.

\section{Analytical strategies}

Descriptive analysis was conducted using SPSS statistics software (v.20; SPSS Inc., Chicago, IL). Confirmatory Factor Analyses (CFA) and Multigroup Analysis (MA) were conducted with Mplus software (version 7.1), in which we have specified all items of RRS-10 as categorical dependent variables (since this measure has only 4 points). As so, the Weighted Least Squares Means and Variance adjusted (WLSMV) was used as the estimation method by default (Muthén, \& Muthén, 1998-2015). It uses polychoric correlation matrix, which provides us a more accurate reproduction of the measured model than Pearson correlations (Holgado-Tello, Chacón-Moscoso, Barbero-García, \& Vila-Abad, 2010). When one or more observed dependent variables are categorical, the delta parameterization is specified as the 
default in Mplus. Thus, for all categorical factor indicators, thresholds are modeled rather than means or intercepts (Muthén, \& Muthén, 1998-2015).

Firstly, a Confirmatory Factor Analysis was conducted in order to confirm the RRS-10 two-factor structure (using the total sample, $N=321$ ). We used a combination of different goodness-of-fit indexes to evaluate the global model adjustment (Kline, 2010). Specifically, we used the Comparative Fit Index (CFI), Tucker-Lewis Index (TLI), Root Mean Square Error of Approximation (RMSEA) and Normed Chi-square ( $\chi 2 / \mathrm{df})$. CFI values $\geq .9$ indicates a good fit and TLI values range from 0 to 1 - the closer to 1 , the better the model fit (Hu \& Bentler, 1999). RMSEA values $\leq .10$ indicates a good fit and $\chi^{2} / \mathrm{df}<5$ indicates an acceptable fit (Marôco 2010; Schumacker \& Lomax, 2004). In addition, local adjustment of the model was assessed by both the standardized factor weights and the individual reliability of the items, taking into account values of $\lambda \geq .40$ (Stevens, 1992) and $R^{2} \geq .20$ (Hooper, Coughlan, \& Mullen, 2008).

Thereafter, a Multigroup Analysis was conducted in order to test whether the RRS-10 two-factor structure would be invariant across three different samples (i.e., general population, college students, and medical sample). For categorical indicators (using WLSMV estimator and delta parameterization), the configural model has factor loadings and thresholds free across groups while the scale factors are fixed at one in all groups. For the same scenario, the metric model has: (1) the factor loadings constrained to be equal in all groups; (2) the scale factors fixed at one in one group (i.e., the one which was defined with the lowest value on the grouping variable), and freely estimated in the other groups. For the current study, the grouping variable comprised the general population, college students and medical samples for which the values of 1, 2 and 3 (respectively) were attributed; (3) the first threshold of each item is constrained to be equal across groups, while the second threshold of the item used to factor identification is held equal in all groups; and (4) factor variances are freely estimated 
across groups (Muthén, \& Muthén, 1998-2015). The chi-square difference test between models was calculated using the DIFFTEST option for WLSMV. Thus, in order to stablish the RRS-10 two-factor structure invariance across groups, the comparison between the metric model and the configural one cannot indicate that constraining factor loadings lead to a fit significant worse (see Muthén, \& Muthén, 1998-2015). Thus, if the metric invariance holds, this means that the two factors of the RRS-10 and its respective indicators (i.e., items) did not differ across groups (Marsh et al., 2017).

Internal consistency was assessed through Cronbach's Alpha, where values of $\alpha>.7$ indicates adequate reliability (Kline, 2010) - previously to correlational analyses, the internal consistency was calculated for all variables in study.

Convergent validity was assessed by Pearson's correlations. Furthermore, in order to compare the magnitude of associations of Brooding (B) and Reflection (R) with other variables in study, a test of the equality of two correlations coefficients obtained from the same sample (i.e., dependent correlations) was performed using Lee's interactive calculator (Lee \& Preacher, 2013). The resulting z-score was considered significant if greater than 1.96 (Kline, 2010). We hypothesized RRS-10 to be positively associated with cognitive fusion (CFQ), psychological inflexibility (AAQ-II) and anxiety, depression and stress symptomatology (DASS-21). Additionally, we predicted that Brooding would present significantly stronger relationships with CFQ, AAQ-II and DASS-21 than Reflection would.

\section{Results}

Table 1 presents the socio-demographic characteristics of the total sample and of each group.

Insert Table 1 here

\section{Confirmatory Factor Analysis}


Regarding the analytical assumptions, there were no outliers and no imputation strategy was conducted, as all analyses were performed with complete data from participants. CFA was conducted using the total sample $(N=321)$. Initially, the RRS-10 original two-factor model was specified (see Fig. 1), where each factor was composed by five items (i.e., Brooding: items 1, 3, 6, 7 and 8; Reflection: items 2, 4, 5, 9 and 10). Insert Fig 1 here

All items presented acceptable values of factor weights and individual reliabilities $(\lambda \geq$ .53 and $\mathrm{R}^{2} \geq .28$, respectively), which indicates a good local adjustment. Additionally, the RRS-10 two-factor structure (as originally proposed by Treynor et al., 2003) presented a good model fit to our data $\left(\chi^{2} / d f=3.89 ; \mathrm{RMSEA}=.095 ; \mathrm{CFI}=.93 ; \mathrm{TLI}=.90\right)$.

\section{Multigroup analysis}

Fig. 2 presents the standardized factor weights and individual reliabilities of the items in each group.

Insert Fig. 2 here

When the three samples were considered simultaneously, the two-factor structure also presented good fit indices $(\chi 2 / d f=1.66 ; \mathrm{RMSEA}=.079 ; \mathrm{CFI}=.94 ; \mathrm{TLI}=.94)$, together with acceptable values of factor weights $(\lambda \geq .48)$ and individual reliabilities $\left(\mathrm{R}^{2} \geq .23\right)$, which indicates a satisfactory local fit. Finally, no significant differences were detected between the metrical and the configural models $\left[\Delta \chi^{2}(16)=18.46 ; p=0.298\right]$, which demonstrates the invariance of the RRS-10 two-factor structure across these groups.

\section{Internal consistency}

Table 2 presents the RRS-10 items' properties (means, standard deviations, corrected item-total correlation and $\alpha$ if item deleted values). All items were contributing to the observed internal consistencies, since none item, if excluded, would increase the Cronbach's Alpha. 
Insert Table 2 here

Cronbach's Alpha values in the total sample $(N=321)$ were $\alpha=.75$ for both the B and R subscales and $\alpha=.81$ for the RRS-10 total score. When considered separately, the R and B subscales presented $\alpha=.82$ and $\alpha=.77$ for general population, $\alpha=.72$ and $\alpha=.68$ for college students and $\alpha=.70$ and $\alpha=.79$ for medical sample, respectively.

\section{Convergent validity}

Table 3 presents the descriptive statistics (means and standard deviations) and the internal consistency of each variable in analysis. Additionally, the correlations between RRS10 (total, brooding and reflection) and other variables in study are presented in Table 4. Insert Table 3 here Insert Table 4 here

Correlational data showed that all variables are associated with each other in the expected directions. Also, as previously hypothesized, when compared with the reflection facet of rumination, brooding presented significantly stronger associations with cognitive fusion $(z$-score $=4.274)$, psychological flexibility $(z$-score $=5.345)$ and psychopathological

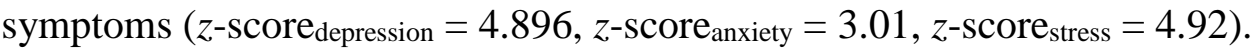

\section{Discussion}

Although the two-factor structure of RRS-10 has showed the most solid evidence in the available literature, it was unclear if this structure would be the same in medical samples. As so, the main goal of this study was to test the invariance of the two-factor structure of RRS-10, considering simultaneously three different samples of women (i.e., general population, college students and medical samples).

The current CFA results confirmed the two-factor structure of RRS-10, as proposed by Treynor and colleagues (2003), and showed good global and local adjustments, as well as 
good internal consistency with Cronbach's Alpha values of .75 (Kline, 2010) for both subscales.

Previous CFA studies have also confirmed the two-factor RRS-10 original structure (Treynor et al, 2003; $\alpha=.72$ [Reflection - R] and $\alpha=.77$ [Brooding - B]) with similar modelfit-indices and Cronbach's Alpha values. Namely, the Schoofs and colleagues $(2010, \alpha=.75$ $[\mathrm{R}]$ and $\alpha=.78[\mathrm{~B}])$, Erdur-Baker and Bugay $(2012 ; \alpha=.77[\mathrm{R}]$ and $\alpha=.75[\mathrm{~B}])$, Hasegawa (2013, $\alpha=.75[\mathrm{R}]$ and $\alpha=.81[\mathrm{~B}])$ and the Thanoi and Klainin-Yobas $(2015, \alpha=.73[\mathrm{R}]$ and $\alpha=$ $.71[B])$ studies.

Thereafter, the Multigroup CFA results have confirmed the invariance of the twofactor structure model of RRS-10. Thus, our results support that the two factors are clearly distinct, even when simultaneously analyzed in medical and non-medical samples, which to our knowledge has never been tested. Nevertheless, further studies of Multigroup CFA are required to ensure the stability of our results - including other sets of medical samples.

Also, the current study has explored the RRS-10 convergent validity, and its results showed that rumination was positively associated with depression, anxiety and stress symptomatology, as well as with psychological processes with a pervasive impact on psychopathology (i.e. cognitive fusion and experiential avoidance). In line with this, previous studies showed that rumination is positively associated with emotional difficulties such as depressive symptoms (Erdur-Baker \& Bugay, 2012; Hasegawa, 2013; Schoofs et al., 2010; Thanoi \& Klainin-Yobas, 2015; Treynor et al., 2003), worry (Hasegawa, 2013; Schoofs et al., 2010), thought suppression (Schoofs et al., 2010), hopelessness, emotional distress, anxiety (Thanoi \& Klainin-Yobas, 2015) and self-preoccupation (Hasegawa, 2013).

These results can be interpreted in light of theoretical approaches that have extensively suggested the nefarious role rumination plays in depression and depression relapse (i.e., by engaging in a specific way of self-focus in which one pays particular attention to one's 
depressive symptoms and its respective consequences; see Nolen-Hoeksema \& Morrow, 1993). Additionally, recent contextual behavioral approaches of psychopathology (e.g., Acceptance and Commitment Therapy - ACT; Hayes et al., 2012) have proposed that rumination can function as an avoidance-based strategy in which a person attempts to control their negative internal experiences (e.g., dysphoric mood) (Cribb et al., 2006). In fact, rumination seems to be significantly correlated with psychopathology indicators when avoidance is involved (Moulds et al., 2007). Furthermore, the psychological inflexibility model of psychopathology (ACT; Hayes et al., 2012) have put forward the hypothesis that cognitive fusion is one of the underlying processes of avoidance. Given that cognitive fusion and rumination are both inherently language-based processes, it can be hypothesized that the nefarious effect of rumination is closely related to the entanglement with the content of ruminative thinking. Indeed, there is recent preliminary data suggesting that cognitive fusion mediates the relationship between rumination and depression symptoms (Lucena-Santos et al., 2017).

It is worth noting that the two distinctive factors that compose rumination, i.e., brooding and reflection, were both positively associated with psychopathological symptoms (i.e., depression, anxiety and stress symptoms), cognitive fusion and experiential avoidance, although brooding presented significantly higher associations with these variables than reflection did. The same pattern was found in previous studies, in which brooding was more strongly correlated with negative psychological processes than reflection (Erdur-Baker \& Bugay, 2010; Hasegawa, 2013; Schoofs et al., 2010; Thanoi \& Klainin-Yobas, 2015; Treynor et al., 2003). These results seem to corroborate the hypothesis that these constructs are distinct dimensions of an underlying pervasive psychological process (i.e., rumination). This goes in line with studies that suggest that although reflection seems to have a less pervasive impact on depression than brooding (Treynor et al., 2003), its role could depend on whether a person 
uses an active or passive coping (Marroquin, Fontes, Scilletta, \& Miranda, 2010). Thus, these data seem to suggest a necessity to further analyze the distinctive impact of brooding and reflection on negative health outcomes.

Regarding clinical and research implications, this study validates the Brazilian Portuguese version of RRS-10, thus providing a valid and sound measure of different dimensions of rumination, allowing rigorous comparisons not only between women from general population and college students samples, but also between those and participants from medical settings (i.e., women with overweight and obesity in weight loss treatment). This allows a more accurate functional analysis of cognitive and behavioral clinical outputs of rumination, which might contribute to a more targeted intervention - one that focuses on the specific impact of different components of ruminations. In fact, a clinical intervention that targets rumination as a monolith, instead of considering its different dimensions and impacts, may be less effective - probably due to the fact that brooding rumination decreases one's ability and/or efficiency to resolve problems in an adaptive way.

Additionally, as mentioned before, ruminative thinking have a deleterious influence not only in psychological and behavioral problems, but it is also related to more negative outcomes in medical settings (e.g., Sansone \& Sansone, 2012; Le Borgne, Boudoukha, Petit, \& Roquelaure, 2017; Hogan \& Linden 2004). Hence, this study also extend the existing literature: it includes data on the role of rumination in a medical sample of particular relevance (i.e., overweight or obese women currently in weight loss treatment), since rumination is associated with higher BMI in people with BMI $\geq 25$ (Tan et al., 2017) and body dissatisfaction is positively related with ruminative thinking in women (e.g., Naumann et al., 2016).

Indeed, patients who reported high levels of body dissatisfaction and brooding rumination (rather than reflective rumination) are those who have the greatest levels of 
dysfunctional eating (Gordon et al., 2012). Moreover, women with obesity who ruminate in response to an experimentally induced increase of body dissatisfaction presented a significant increase in distress about body feelings, while the increase in negative mood caused by the induction remained unchanged. In contrast, these scores returned to baseline levels in those who applied acceptance strategies (Svaldi et al., 2013). Thus, in the context of women with overweight undergoing a weight loss treatment, the clinician should be aware of the crucial relevance of assessing the presence of brooding rumination. If high levels of brooding are detected, clinicians should implement therapeutic strategies that would buffer its impact on psychological suffering, such as implementing an acceptance- and mindfulness-based clinical approach (Deyo, Wilson, Ong, \& Koopman, 2009; Naumann et al., 2016).

It is suggested that people with chronic illness use rumination as a coping strategy to deal with the physical and emotional consequences related to their disease. However, by using this strategy patients can increase the burden of illness, as they may be more likely to experience an intensification of negative affect and physical impairments - which could also become even more prolonged in time (see Soo et al., 2009). Therefore, by providing a measure which has its factorial invariance empirically supported, this study represents a scientific progress for an accurate evaluation of relevant outcomes in this population.

Moreover, this study provides data supporting the use of RRS in non-medical samples, such as samples from general population and of college students. This is important since rumination is a transdiagnostic process extensively found in those samples. Therefore, the availability of the Brazilian version of RRS-10 might contribute to further understanding of maladaptive emotional regulation strategies in Brazilian samples.

It is important to take into consideration some limitations of the current study. One is related with the cross-section nature of its design, which prevents us from drawing conclusions regarding causality between variables. In addition, given our samples were 
convenience based and composed only of women, generalization of these findings should be established with caution. Furthermore, since our study did not include samples composed of participants with mental health diagnoses, extrapolation of our findings to these populations is unwarranted.

Future directions in the study of RRS-10 might include the development of an experimental design in which the construct validity of rumination is corroborated by correlating results of the instrument with results from a rumination task. Additionally, future studies with the Brazilian Portuguese version of RRS-10 should consider a longitudinal design that includes a test-retest reliability analysis, in order to test the temporal stability of the instrument. Finally, the differentiated impact of both brooding and reflection on psychopathological symptoms should be addressed in future research. Specifically, a multigroup mediational analysis in non-clinical and clinical samples (including participants with mental health diagnoses) might contribute for shedding an important light on the relative impact of brooding and reflection according to sample group, as well as to help understanding the path through which these forms of rumination impact psychopathological symptoms.

\section{References}

Abbott, M. J., \& Rapee, R. M. (2004). Post-event rumination and negative self-appraisal in social phobia before and after treatment. Journal of Abnormal Psychology, 113(1), 136144. doi:10.1037/0021-843X.113.1.136

Alloy, L. B., Abramson, L. Y., Hogan, M. E., Whitehouse, W. G., Rose, D. T., Robinson, M. S., Kim, R. S., \& Lapkin, J. B. (2000). The Temple-Wisconsin Cognitive Vulnerability to Depression Project: lifetime history of axis I psychopathology in individuals at high and low cognitive risk for depression. Journal of Abnormal Psychology, 109(3), 403418. doi:10.1037/0021-843X.109.3.403

Armey, M. F., Fresco, D. M., Moore, M. T., Mennin, D. S., Turk, C. L., Heimberg, R. G., ... Alloy, L. B. (2009). Brooding and pondering: Isolating the active ingredients of depressive rumination with exploratory factor analysis and structural equation modeling. Assessment, 16, 315-327. doi: 10.1177/1073191109340388 
Arrindell, W. A., \& Van der Ende. J. (1985). An empirical test of the utility of the observations-to-variables ratio in factor and components analysis. Applied Psychological Measurement, 9, 165-178.

Barbosa, L. M. (2013). Terapia de Aceitação e Compromisso e Validação do Acceptance and Action Questionnaire II: Contribuições para Avaliação de Processo em Psicoterapia. Dissertação de Mestrado, Instituto de Psicologia, Universidade de Brasília, Brasília.

Bentler, P. M., \& Chou, C. (1987). Practical issues in structural modeling. Sociological Methods and Research, 16, 78-117.

Bond, F. W., Hayes, S. C., Baer, R. A., Carpenter, K. M., Guenole, N., Orcutt, H. K., Waltz, T., Zettle, R. D. (2011). Preliminary Psychometric Properties of the Acceptance and Action Questionnaire-II: A Revised Measure of Psychological Inflexibility and Experiential Avoidance. Behavior Therapy, 42(4), 676-688. doi:10.1016/j.beth.2011.03.007

Burwell, R. A., \& Shirk, S. R. (2007). Subtypes of rumination in adolescence: associations between brooding, reflection, depressive symptoms, and coping. Journal for the Society of Clinical Child and Adolescent Psychology, 36(1), 56-65. doi:10.1080/15374410709336568

Cassepp-Borges, V., Balbinotti, M. A. A., \& Teodoro, M. L. M. (2010). Tradução e validação de conteúdo: Uma proposta para a adaptação de instrumentos. In L. Pasquali (Org.). Instrumentação psicológica: Fundamentos e práticas (pp. 506-520). Porto Alegre: Artmed.

Conway, M., Csank, P. A., Holm, S. L., \& Blake, C. K. (2000). On assessing individual differences in rumination on sadness. Journal of Personality Assessment, 75(3), 404425. doi:10.1207/S15327752JPA7503_04

Cribb, G., Moulds, M. L., \& Carter, S. (2006). Rumination and Experiential Avoidance in Depression. Behaviour Change, 23(3), 165-176. doi:10.1375/bech.23.3.165

Deyo, M., Wilson, K. A., Ong, J., Koopman, C. (2009). Mindfulness and rumination: does mindfulness training lead to reductions in the ruminative thinking associated with depression? Explore: The Journal of Science \& Healing, 5(5), 265-271. doi: 10.1016/j.explore.2009.06.005.

Dinis, A., Pinto-Gouveia, J., Duarte, C., \& Castro, T. (2012). Estudo de validação da versão portuguesa da Escala de Respostas Ruminativas - Versão Reduzida. Psychologica, 54, 175-202.

Ehring, T., \& Ehlers, A. (2014). Does rumination mediate the relationship between emotion regulation ability and posttraumatic stress disorder? European Journal of Psychotraumatology. doi:10.3402/ejpt.v5.23547

Erdur-Baker, Ö., \& Bugay, A. (2010). The short version of ruminative response scale: Reliability, validity and its relation to psychological symptoms. Procedia Social and Behavioral Sciences, 5, 2178-2181. doi:10.1016/j.sbspro.2010.07.433 
Erdur-Baker, Ö., \& Bugay, A. (2012). The Turkish version of the Ruminative Response Scale: An examination of its reliability and validity. The International Journal of Educational and Psychological Assessment, 10(2), 1-16.

Extremera, N., \& Fernández-Berrocal, P. (2006). Validity and reliability of Spanish versions of the Ruminative Responses Scale-Short Form and the Distraction Responses Scale in a sample of Spanish high school and college students. Psychological Reports, 98(1), 141-150. doi:10.2466/PR0.98.1.141-150

Fabrigar, L. R., Wegener, D. T., MacCallum, R. C., \& Strahan, E. J. (1999). Evaluating the use of exploratory factor analysis in psychological research. Psychological Methods, 4, 272-299.

Finucane, M. M., Stevens, G. A., Cowan, M. J., Danaei, G., Lin, J. K., Paciorek, C. J., Singh, G. M., Gutierrez, H. R., Lu, Y., Bahalim, A. N., Farzadfar, F., Riley, L.M., Ezzati, M., Global Burden of Metabolic Risk Factors of Chronic Diseases Collaborating Group (2011). National, regional, and global trends in body-mass index since 1980: systematic analysis of health examination surveys and epidemiological studies with 960 countryyears and 9.1 million participants. Lancet, 377(9765), 557-567.

Gillanders, D. T., Bolderston, H., Bond, F. W., Dempster, M., Flaxman, P. E., Campbell, L., Kerr, S., Tansey, L., Noel P., Ferenbach, C., Masley, S., Roach, L., Lloyd, J., May, L., Clarke, S., Remington, B. (2014). The development and initial validation of The Cognitive Fusion Questionnaire. Behavior Therapy, 45(1), 83-101, doi:10.1016/j.beth.2013.09.001

Gordon, K. H., Holm-Denoma, J. M., Troop-Gordon, W., \& Sand, E. (2012). Rumination and body dissatisfaction interact to predict concurrent binge eating. Body Image, 9(3), 352357. doi:10.1016/j.bodyim.2012.04.001

Greco, L.A., Lambert, W., \& Baer, R. A. (2008). Psychological inflexibility in childhood and adolescence: Development and evaluation of the Avoidance and Fusion Questionnaire for Youth. Psychological Assessment, 20(2), 93-102. doi: 10.1037/1040-3590.20.2.93

Griffith, J. W., \& Raes, F. (2015). Factor structure of the Ruminative Responses Scale: A community-sample Study. European Journal of Psychological Assessment, 31(4), 247 253. doi: 10.1027/1015-5759/a000231

Guadagnoli, E., \& Velicer W. F. (1998). Relation of sample size to the stability of component patterns. Psychological Bulletin, 103, 265-275.

Hankin, B. L., Abramson, L. Y., Moffitt, T. E., Silva, P. A., McGee, R., \& Angell, K. E. (1998). Development of depression from preadolescence to young adulthood: emerging gender differences in a 10-year longitudinal study. Journal of Abnormal Psychology, 107(1), 128-140. doi:10.1037/0021-843X.107.1.128

Hasegawa, A. (2013). Translation and initial validation of the Japanese version of the Ruminative Responses Scale. Psychological Reports, 112(3), 716-726. doi:10.2466/02.08.PR0.112.3.716-726 
Hatcher, L. (1994). A step-by-step approach to using the SAS system for factor analysis and structural equation modeling. Cary, NC: SAS Institute, Inc.

Hayes, S. C., Strosahl, K. D., \& Wilson, K. G. (2012). Acceptance and commitment therapy: The process and practice of mindful change (2nd ed.). The Guilford Press: New York.

Hernández-Nieto, R. (2002). Contribuiciones al análisis estadístico. Venezuela: IESINFO.

Hilt, L. M., Cha, C. B., \& Nolen-Hoeksema, S. (2008). Nonsuicidal self-injury in young adolescent girls: Moderators of the distress-function relationship. Journal of Consulting and Clinical Psychology, 76(1), 63-71. doi:10.1037/0022-006X.76.1.63

Hogan, B. E., \& Linden, W. (2004). Anger response styles and blood pressure: At least don't ruminate about it! Annals of Behavioral Medicine, 27(1), 38-49. doi:

10.1207/s15324796abm2701_6

Holgado-Tello, F., Chacón-Moscoso, S., Barbero-García, I., \& Vila-Abad, E. (2010). Polychoric versus Pearson correlations in exploratory and confirmatory factor analysis of ordinal variables. Quality \& Quantity, 44(1), 153-166. doi:10.1007/s11135-008-9190-y

Hooper, D., Coughlan, J., \& Mullen, M. R. (2008). Structural equation modelling: Guidelines for determining model fit. Journal of Business Research Methods, 6(1), 53-60.

Hoyer, J., Becker, E. S., \& Margraf, J. (2002). Generalized anxiety disorder and clinical worry episodes in young women. Psychological Medicine, 32(7), 1227-1237. doi:10.1017/S0033291702006360

Hu, L.T., \& Bentler, P.M. (1999). Cutoff criteria for fit indexes in covariance structure analysis: Conventional criteria versus new alternatives. Structural Equation Modeling, 6(1), 1-55. doi:10.1080/10705519909540118

Ingram, R. E., Cruet, D., Johnson, B. R., \& Wisnicki, K. S. (1988). Self-focused attention, gender, gender role, and vulnerability to negative affect. Journal of Personality and Social Psychology, 55(6), 967-978.

Kass, R. A., \& Tinsley, H. E. A. (1979). Factor analysis. Journal of Leisure Research, 11, $120-138$.

Kline, R. B. (2010). Principles and practice of structural equation modeling (3rd ed.). New York: Guilford Press.

Knowles, R., Tai, S., Christensen, I., \& Bentall, R. (2005). Coping with depression and vulnerability to mania: A factor analytic study of the Nolen-Hoeksema (1991) Response Styles Questionnaire. British Journal of Clinical Psychology, 44(1), 99-112. doi:10.1348/014466504X20062

Le Borgne, M., Boudoukha, A. H., Petit, A., \& Roquelaure, Y. (2017). Chronic low back pain and the transdiagnostic process: How do cognitive and emotional dysregulations contribute to the intensity of risk factors and pain? Scandinavian Journal of Pain. doi: 10.1016/j.sjpain.2017.08.008. 
Lee, S., \& Kim, W. (2014). Cross-cultural adaptation, reliability, and validity of the revised Korean version of Ruminative Response Scale. Psychiatry Investigation, 11(1), 59-64. doi:10.4306/pi.2014.11.1.59

Lee, I. A., \& Preacher, K. J. (2013, September). Calculation for the test of the difference between two dependent correlations with one variable in common [Computer software]. Available from http://quantpsy.org.

Lovibond, S. H., \& Lovibond, P. F. (1995). Manual for the Depression, Anxiety and Stress Scales. Sydney: Psychology Foundation.

Lucena-Santos, P., Carvalho, S., Pinto-Gouveia, J., Gillanders, D., \& Oliveira, M.S. (2017). Cognitive Fusion Questionnaire: Exploring measurement invariance across three groups of Brazilian women and the role of cognitive fusion as a mediator in the relationship between rumination and depression. Journal of Contextual Behavioral Science, 6(1), 53-62. doi.10.1016/j.jcbs.2017.02.004

Lyubomirsky, S., \& Nolen-Hoeksema, S. (1993). Self-perpetuating properties of dysphoric rumination. Journal of Personality and Social Psychology, 65(2), 339-349. doi:10.1037/0022-3514.65.2.339

Marsh, H. W., Guo, J., Nagengast, B., Parker, P. D., Asparouhov, T., Muthén, B., \& Dicke, T. (2017). What to do when scalar invariance fails: The extended alignment method for multi- group factor analysis comparison of latent means across many groups. Psychological Methods, doi: 10.1037/met0000113

Marôco, J. (2010). Analysis of Structural Equations: Theoretical foundations, software and applications. Pero Pinheiro: Report Number.

Marroquin, B. M., Fontes, M., Scilletta, A., \& Miranda, R. (2010). Ruminative subtypes and coping responses: Active and passive pathways to depressive symptoms. Cognition and Emotion, 24(8), 1446-1455. doi:10.1080/02699930903510212

Mellings, T. M. B., \& Alden, L. E. (2000). Cognitive processes in social anxiety: The effects of self-focus, rumination and anticipatory processing. Behaviour Research and Therapy, 38(3), 243-257. doi:10.1016/S0005-7967(99)00040-6

Morrison, R., \& O'Connor, R. C. (2005). Predicting psychological distress in college students: The role of rumination and stress. Journal of Clinical Psychology, 61(4), 447-460.

Moulds, M. L., Kandris, E., Starr, S., \& Wong, A. C. M. (2007). The relationship between rumination, avoidance and depression in a non-clinical sample. Behaviour Research and Therapy, 45(2), 251-261. doi:10.1016/j.brat.2006.03.003

Muthén, L. K., \& Muthén, B. O. (1998-2015). Mplus User's Guide (7th Ed.). Los Angeles, CA: Muthén \& Muthén.

Naumann, E., Tuschen-Caffier, B., Voderholzer, U., Schäfer, J., \& Svaldi, J. (2016). Effects of emotional acceptance and rumination on media-induced body dissatisfaction in anorexia and bulimia nervosa. Journal of Psychiatric Research, 82, 119-125. doi: 10.1016/j.jpsychires.2016.07.021 
Nolen-Hoeksema, S. (1991). Responses to depression and their effects on the duration of depressive episodes. Journal of Abnormal Psychology, 100(4), 569-582. doi:10.1037/0021-843X.100.4.569

Nolen-Hoeksema, S. (2004). The Response Styles Theory. In C. Papageorgiu, A. Wells (Eds.). Depressive Rumination: Nature, theory and treatment (pp. 107-124). Chichester: John Wiley Sons.

Nolen-Hoeksema, S., \& Morrow, J. (1991). A prospective study of depression and posttraumatic stress symptoms after a natural disaster: The 1989 Loma Prieta Earthquake. Journal of Personality and Social Psychology, 61(1), 115-121. doi:10.1037/0022-3514.61.1.115

Nolen-Hoeksema, S., \& Morrow, J. (1993). Effects of rumination and distraction on naturally occurring depressed mood. Cognition \& Emotion, 7(6), 561-570. doi:10.1080/02699939308409206

Nunnally, J. C. (1978). Psychometric theory (2nd Ed.). New York: McGraw-Hill.

O'Connor, R. C., \& Noyce, R. (2008). Personality and cognitive processes: Self-criticism and different types of rumination as predictors of suicidal ideation. Behaviour Research and Therapy, 46(3), 392-401. doi:10.1016/j.brat.2008.01.007

Raes, F., \& Hermans, D. (2008). On the mediating role of subtypes of rumination in the relationship between childhood emotional abuse and depressed mood: Brooding versus reflection. Depression and Anxiety, 25, 1067-1070. doi: 10.1002/da.2044

Sansone, R. A., \& Sansone, L. A. (2012). Rumination: Relationships with physical health. Innovations in Clinical Neuroscience, 9(2), 29-34.

Schoofs, H., Hermans, D., \& Raes, F. (2010). Brooding and reflection as subtypes of rumination: Evidence from confirmatory factor analysis in nonclinical samples using the Dutch Ruminative Response Scale. Journal of Psychopathology and Behavioral Assessment, 32(4), 609-617. doi:10.1007/s10862-010-9182-9

Schumacker, R. E., \& Lomax, R. G. (2004). A beginner's guide to structural equation modeling (2nd ed.). Mahwah, NJ: Lawrence Erlbaum Associates.

Simonson, J., Mezulis, A., \& Davis, K. (2011). Socialized to ruminate? Gender role mediates the sex difference in rumination for interpersonal events. Journal of Social and Clinical Psychology, 30(9), 937-959. doi:10.1521/jscp.2011.30.9.937

Soo, H., Burney, S., \& Basten, C. (2009). The role of rumination in affective distress in people with a chronic physical illness: A review of the literature and theoretical formulation. Journal of Health Psychology, 14(7), 956-966. doi: 10.1177/1359105309341204.

Soper, D. S. (2017). A-priori sample size calculator for Structural Equation Models [Software]. Available from 〈http://www.danielsoper.com/statcalc〉.

Stevens, J. P. (1992). Applied multivariate statistics for the social sciences (2nd ed.). Hillsdale, NJ: Erlbaum. 
Svaldi, J., Naumann, E., Trentowska, M., Lackner, H. K., \& Tuschen-Caffier, B. (2013). Emotion regulation and its influence on body-related distress in overweight women. Journal of Experimental Psychopathology, 4(5), 529-545. doi: 10.5127/jep.028712

Tan, Y., Xin, X., Wang, X., \& Yao, S. (2017). Cognitive emotion regulation strategies in chinese adolescents with overweight and obesity. Childhood Obesity. doi: 10.1089/chi.2017.0123

Thanoi, W., \& Klainin-Yobas, P. (2015). Assessing rumination response style among undergraduate nursing students: A construct validation study. Nurse Education Today. doi:10.1016/j.nedt.2015.01.001

Treynor, W., Gonzalez, R., \& Nolen-Hoeksema, S. (2003). Rumination Reconsidered: A psychometric analysis. Cognitive Therapy and Research, 27(3), 247-259. doi:10.1023/A:1023910315561

Velicer, W. F., \& Fava, J. L. (1998). Effects of variable and subject sampling on factor pattern recovery. Psychological Methods, 3(2), 231-251.

Vignola, R. C., \& Tucci, A. M. (2014). Adaptation and validation of the depression, anxiety and stress scale (DASS) to Brazilian Portuguese. Journal of Affective Disorders, 155, 104-109. doi:10.1016/j.jad.2013.10.031

Wang, S. B., Lydecker, J. A., \& Grilo, C. M. (2017). Rumination in patients with binge-eating disorder and obesity: Associations with eating-disorder psychopathology and weightbias internalization. European Eating Disorders Review, 25(2), 98-103. doi: 10.1002/erv.2499.

Watkins, E. R. (2008). Constructive and unconstructive repetitive thought. Psychological Bulletin, 134(2), 163-206. doi:10.1037/0033-2909.134.2.163,

Whitmer, A., \& Gotlib, I. H. (2011). Brooding and reflection reconsidered: A factor analytic examination of rumination in currently depressed, formerly depressed, and never depressed individuals. Cognitive Therapy and Research, 35(2), 99-107. doi:10.1007/s10608-011-9361-3 
Table 1

Sample Characteristics

\begin{tabular}{|c|c|c|c|c|c|c|c|c|}
\hline & \multicolumn{2}{|c|}{$\begin{array}{l}\text { Total Sample } \\
\qquad(N=321)\end{array}$} & \multicolumn{2}{|c|}{$\begin{array}{l}\text { General Population Sample } \\
\qquad(n=106)\end{array}$} & \multicolumn{2}{|c|}{$\begin{array}{l}\text { College Students Sample } \\
\qquad(n=115)\end{array}$} & \multicolumn{2}{|c|}{$\begin{array}{l}\text { Medical Sample } \\
\quad(n=100)\end{array}$} \\
\hline & $M(S D)$ & Min Max & $M(S D)$ & Min $\operatorname{Max}$ & $M(S D)$ & Min $\quad$ Max & $M(S D)$ & Min Max \\
\hline Age & $34.52(12.18)$ & 60 & $35.07(10.54)$ & 25 & $25.77(8.98)$ & 18 & $43.30(10.10)$ & 22 \\
\hline Years of Education & $12.25(3.56)$ & 25 & $12.92(3.79)$ & 23 & $13.93(2.43)$ & 25 & $9.64(2.88)$ & 16 \\
\hline \multirow[t]{2}{*}{ BMI } & $28.75(8.66)$ & 65 & $25.56(4.82)$ & 41 & $23.20(4.30)$ & 42 & $38.57(7.28)$ & 25 \\
\hline & $N$ & $\%$ & $n$ & $\%$ & $n$ & $\%$ & $n$ & $\%$ \\
\hline \multicolumn{9}{|l|}{ Marital status } \\
\hline Married/cohabiting & 133 & 41.4 & 41 & 38.3 & 25 & 21.6 & 68 & 68 \\
\hline Divorced & 21 & 6.5 & 16 & 14.7 & 3 & 2.7 & 2 & 2 \\
\hline Widowed & 12 & 3.6 & 3 & 2.9 & 0 & 0 & 8 & 8 \\
\hline Single & 156 & 48.5 & 46 & 44.1 & 87 & 75.7 & 22 & 22 \\
\hline \multicolumn{9}{|l|}{ Occupational status } \\
\hline Retired & 15 & 4.8 & 0 & 0 & 0 & 0 & 15 & 15 \\
\hline Employed & 182 & 56.6 & 78 & 74 & 52 & 45 & 51 & 51 \\
\hline Unemployed & 124 & 38.6 & 28 & 26 & 63 & 55 & 34 & 34 \\
\hline
\end{tabular}

Note $:$ Max= maximum; Min= minimum; $\mathrm{SD}=$ Standard Deviation; $\mathrm{BMI}=$ Body Mass Index 
Table 2

Means, standard deviations, corrected item-total correlation and Cronbach's Alpha if item deleted for RRS-10 items $(N=321)$

\begin{tabular}{lccccc}
\hline Factor & & $M$ & $S D$ & $\begin{array}{c}\text { Corrected item- } \\
\text { total correlation }\end{array}$ & $\begin{array}{c}\alpha \text { if item } \\
\text { deleted }\end{array}$ \\
\hline Reflection & Item 2 & 2.59 & .96 & .48 & .72 \\
& Item 4 & 2.32 & 1.06 & .56 & .69 \\
& Item 5 & 2.79 & .96 & .51 & .71 \\
& Item 9 & 2.40 & 1.0 & .60 & .67 \\
\multirow{5}{*}{ Brooding } & Item 10 & 2.14 & 1.0 & .43 & .73 \\
& Item 1 & 1.97 & .92 & .48 & .72 \\
& Item 3 & 2.40 & 1.01 & .44 & .73 \\
& Item 6 & 2.71 & .96 & .49 & .72 \\
& Item 7 & 1.92 & 1.09 & .57 & .68 \\
& Item 8 & 2.31 & 1.04 & .61 & .67 \\
\hline \multirow{7}{*}{ Rumination } & Total & 23.55 & 6.07 & -- & -- \\
\hline
\end{tabular}

Note: $\mathrm{M}=$ Mean; $\mathrm{SD}=$ Standard Deviation; $\alpha=$ Cronbach's Alpha 
Table 3

Means, standards deviation and Cronbach's Alpha for the variables in analysis $(N=321)$

\begin{tabular}{lrrr}
\hline Variable & \multicolumn{1}{l}{$M$} & \multicolumn{1}{l}{$\alpha$} \\
\hline Rumination & 23.55 & 6.07 & 0.81 \\
$\quad$ Brooding & 11.3 & 3.56 & 0.75 \\
$\quad$ Reflection & 12.24 & 3.55 & 0.75 \\
Cognitive Fusion & 23.24 & 10.89 & 0.93 \\
Psychological Inflexibility & 20.97 & 10.95 & 0.93 \\
Depression & 4.72 & 5.11 & 0.89 \\
Anxiety & 4.27 & 4.55 & 0.84 \\
Stress & 7.74 & 4.91 & 0.85 \\
\hline
\end{tabular}

Note: $M=$ Mean; $S D=$ Standard Deviation; $\alpha=$ Cronbach's Alpha 
Table 4

Correlation between RRS-10 and variables in study $(N=321)$

\begin{tabular}{|c|c|c|c|c|c|c|c|c|}
\hline Variable & RRS-10 & Brooding & Reflection & CFQ-7 & AAQ-II & Depression & Anxiety & Stress \\
\hline RRS-10 & 1 & & & & & & & \\
\hline Brooding & $.85 * *$ & 1 & & & & & & \\
\hline Reflection & $.85 * *$ & $.45 * *$ & 1 & & & & & \\
\hline CFQ-7 & $.56^{* *}$ & $.61 * *$ & $.34 * *$ & 1 & & & & \\
\hline AAQ-II & $.57 * *$ & $.65^{* *}$ & $.32 * *$ & $.79 * *$ & 1 & & & \\
\hline Depression & $.60 * *$ & $.53 * *$ & $.19 * *$ & $.60 * *$ & $.66 * *$ & 1 & & \\
\hline Anxiety & $.35^{* *}$ & $.41 * *$ & $.19 * *$ & $.52 * *$ & $.53 * *$ & $.72 * *$ & 1 & \\
\hline Stress & $.52 * *$ & $.60 * *$ & $.28 * *$ & $.64 * *$ & $.66 * *$ & $.74 * *$ & $.71 * *$ & 1 \\
\hline
\end{tabular}

Note: $* *$ Correlation is significant at 0.01 level; RRS-10= Ruminative Responses Scale - Short version; CFQ-7 = Cognitive Fusion Questionnaire - short version; AAQ-II= Acceptance and Action Questionnaire short version 


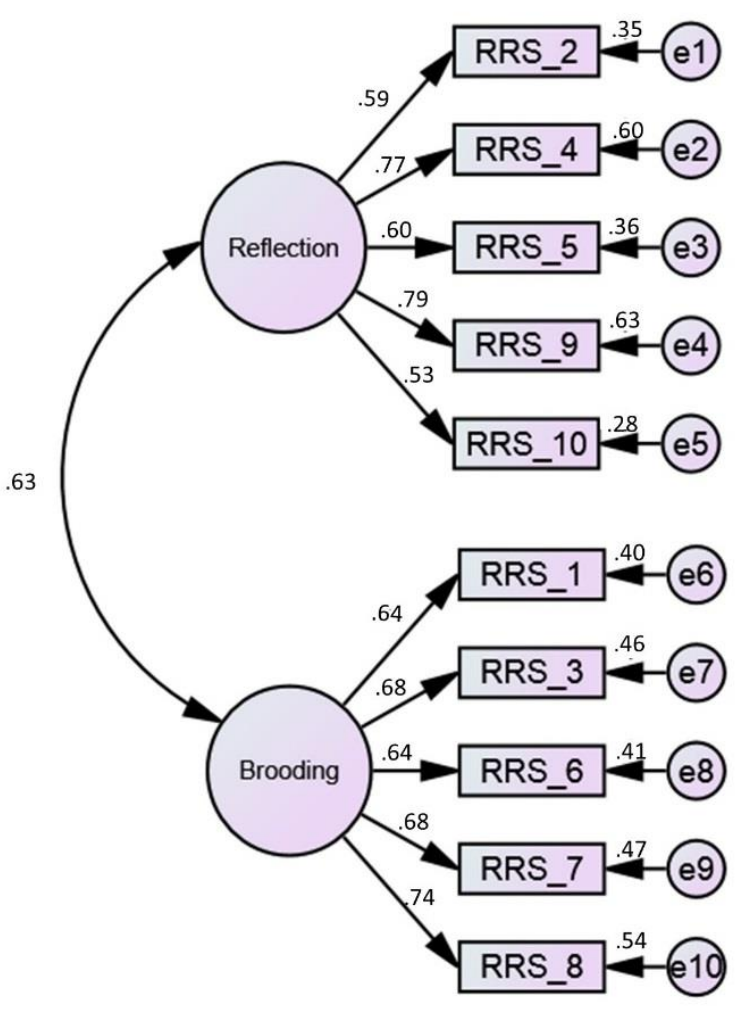

Figure 1. Standardized factor weights and individual reliabilities of the RRS-10's items $(N=321) . \chi^{2}(34)=132.50 ; \chi^{2} / d f=3.89 ; p<0.001 ;$ CFI $=.93 ;$ TLI $=.90 ;$ RMSEA $=.095$; $p<0.001$ 
Medical Sample

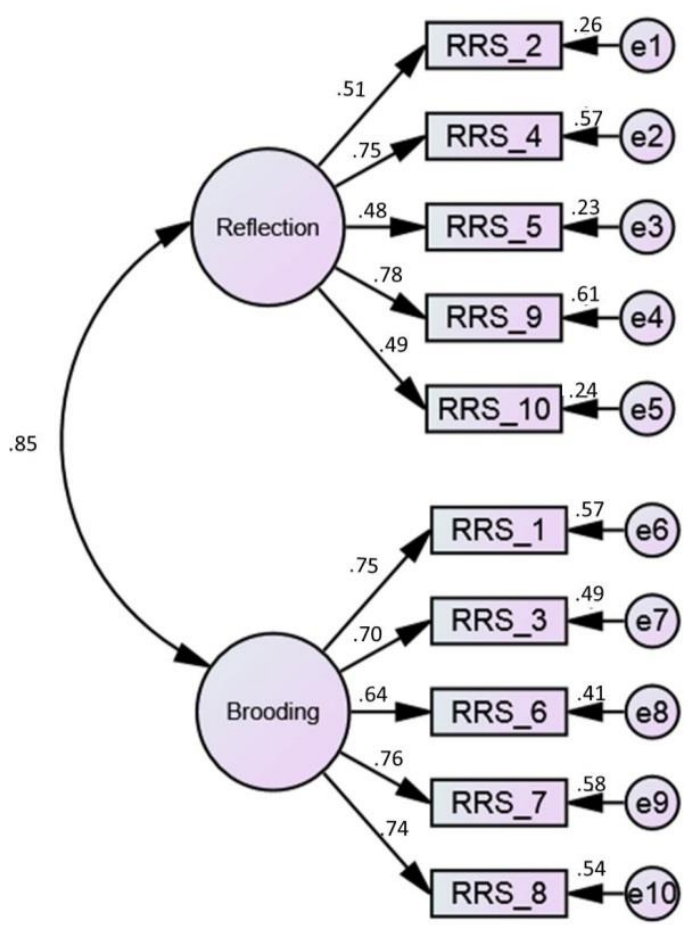

College Students Sample

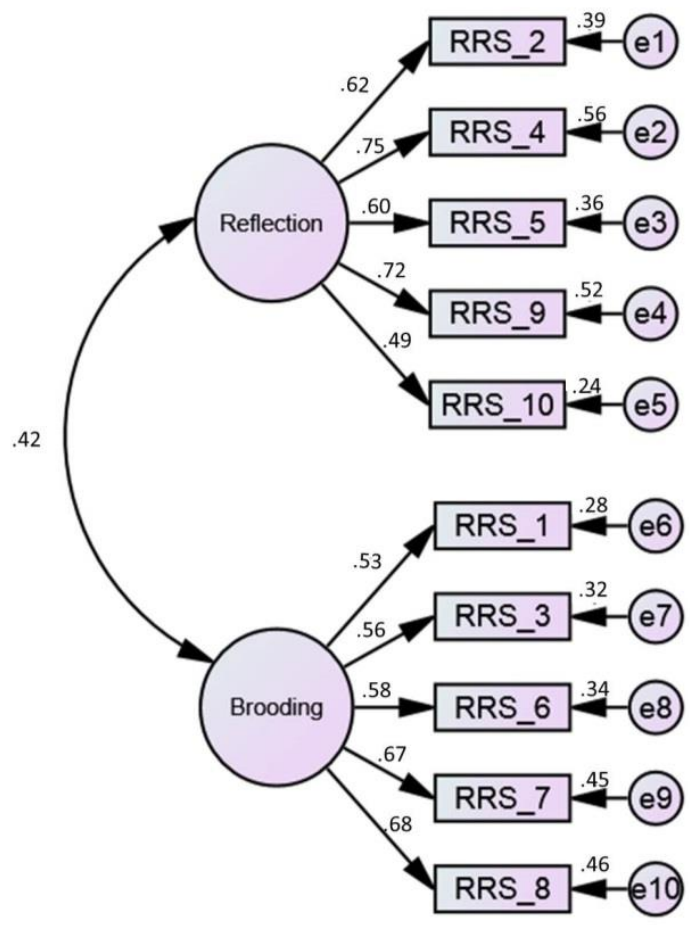

Sample from the general population

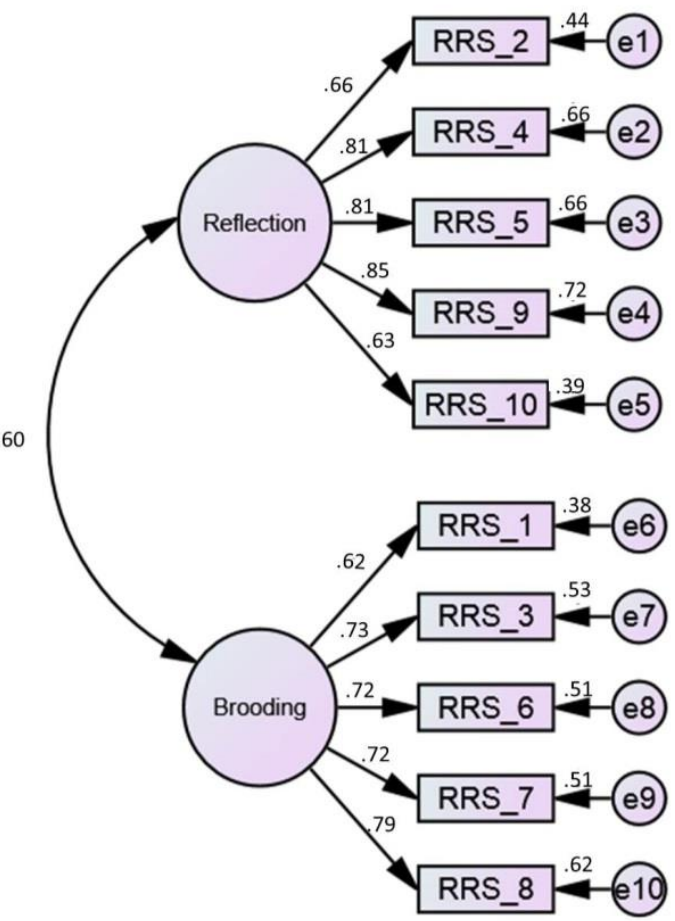

Figure 2. Standardized factor weights and individual reliabilities of the RRS-10's items in each sample (i.e., general population, college students and medical samples). $\chi^{2}(154)=256.03 ; \chi^{2} / d f=1,66 ; p<0.001 ;$ CFI $=.94 ;$ TLI $=.94 ;$ RMSEA $=.079 ; p=.005$ 